\title{
History of Education with Angela Giallongo and Her Snake Women
}

\author{
Interview with Angela Giallongo
}

\section{Patrizia Caraffi \\ University of Bologna \\ Anna C. Forster (translation)}

Angela Giallongo earned a Ph.D. (1976, on the exclusion of women in ancient Greek culture) in History of Education from the University of Urbino, where she is now Professor in the Department of Communication Sciences, and Humanistic and International Studies (DISCUI); she is also a visiting scholar at different universities around Europe and Mexico. She strongly believes that history is not a purely academic activity, and she is known to general readers primarily for her writings on childhood in the Middle Ages, but also for her award-winning book The Adventures of the Gaze (Dedalo, 1995), on public education strategies in pre-modern societies, and her works on the history of European informal education. Her latest publication, The Historical Enigma of the Snake Woman from Antiquity to the $21^{\text {st }}$ Century, won the First National Award for Women's Writing and Studies in Italy in 2013, and in 2014 was a Finalist in a national competition sponsored by the Italian Publishers Association and National Research Council (CNR). In 2015, it also received an encomium from the Italian Center for Historical Educational Research.

Giallongo's research and courses are mainly focussed on the long history of informal educational processes and phenomena in pre-modern culture, with an emphasis on the ancient world, and Medieval and Early-Modern Europe. She has a

ISSN 2560-8371

DOI: 10.24908/encounters.v20i1.13452 
particular interest in exploring public teachings on the human body and sensorial hierarchy, and visual primacy, as well as popular beliefs and stereotypes regarding women and children in secular didactic literature and artistic images; and the link between the emotional 'regimes' and imaginaries in the traditions of pre-modern societies that shaped contemporary Western culture. Some of her investigations are based on the written (the vernacular didactic literature) and visual sources directed at the French, Spanish and Italian female public during the 13th and 14th centuries. Other analyses document the social representations of childhood in the Middle Ages and gender asymmetry, correlated to the symbols that have fuelled conflicting emotional dynamics with Otherness. Her current research explores the imaginary and emotions in the Western history of gender education.

\section{Conversation}

Angela Giallongo speaks to Patrizia Caraffi about her latest book, The Historical Enigma of the Snake Woman from Antiquity to the $21^{\text {st }}$ century (Cambridge Scholars Publishing, 2017), which delves deep into the "snake women" - Western archetypes that have coached lives across the centuries from prehistory to the cyborg era.

\section{Patrizia Caraffi: When did you know you were going to write this book about the Snake Woman? Why did you call it "The Historical Enigma"?}

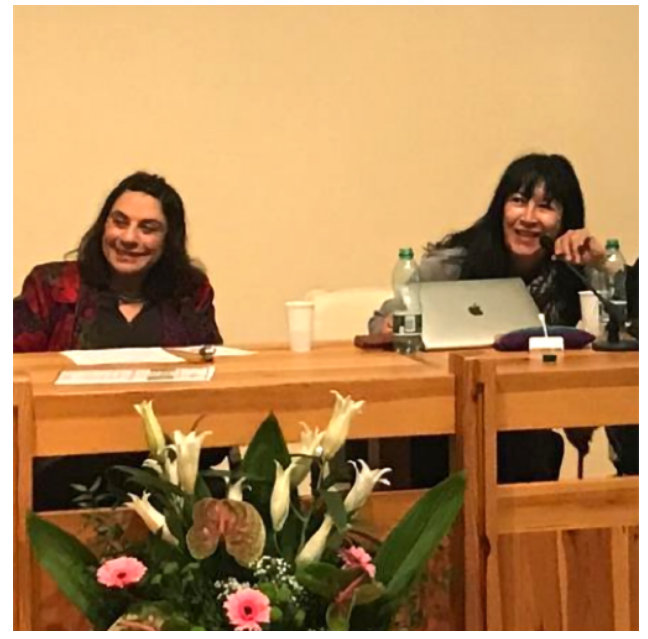

Angela Giallongo and Patrizia Caraffi

Angela Giallongo: First of all, I have to say that it all began with the myth of the Gorgon, a figure that has enchanted me since childhood; when, at school, I asked why she had serpents instead of hair and why her eyes could turn a man to stone, the answer was invariably, "that's just how it is." Unfortunately, it appears that even today things haven't changed much; from what a lot of Italian undergraduates tell me, they learned to hate history at school, because it is even today being taught in a paralysingly dull manner - it is like standing on a sidewalk where anonymous, impersonal faces parade without emotion or imagination. This is precisely how to quash an insatiable desire to understand the past. As for me, it wasn't until university that I was able to quench my thirst for knowledge, when I was given the tools to find answers to vital questions about the history of Education.

At an early stage in my academic doctoral degree, I began to wonder why gender hierarchy had been the cornerstone of European history, and how Western ideas about children had evolved. There are indeed many underlying dynamics that set the history 
of women and children apart. Both these histories require us to use a long-term perspective: they are focal points in the education historiography debate, and it is impossible to find answers to such questions by looking at just one bit of the background. I learned that behind every enigmatic phenomenon there is undoubtedly a symbol, and every symbol is a doorway onto the historical realm. Eyes that kill and serpentine locks are symbols. In this way, the Gorgon Medusa is one of the most ingenious ancient Greek inventions, and is an enduring figment of humanity's collective imaginary, past and present.

However, even though we all grew up with her, we have forgotten her meaning. I thought it would be worthwhile to explore the complicated network of stories about this fictional figure, the most well known among Snake Women. All of these twisting mythological creatures have been key players in the patriarchal system of education since the days of Homer.

\section{PC: This begs the question, what kind of meaning is hidden beneath the stories of the Gorgon?}

AG: It is a complex question. Medusa is a viral archetype that has left a deep furrow. Her myth breathes life into the dusty way of relations between the sexes, compelling us to engage with the fascinating theme of the gaze, which inevitably leads directly to the hot current of menstrual blood. As my research shows, following her deadly eyes is an instructive act.

\section{PC: So, by deciphering symbols we can better understand the consequences of a long series of circumstances and choices?}

AG: I think that is the case, Patrizia. On closer inspection, the history of education reveals a ceaseless flow of symbols. Look at the generations of educators, preceptors, tutors and teachers who have taught us of long-dead civilizations and their protagonists. Primary, secondary, high schools and universities, especially in Europe, charged with the task of instructing the future leaders of the world, have been operating under the conviction that ancient Greece and Rome were the founding stones of culture. Even now, the ideas and gender roles they preach are difficult to shake. It is therefore entirely legitimate to ask just how and to what extent the myths and tales of Medusa have influenced our ruling classes.

What emotions did these stories shape? Did they promote a sense of equality, or are we still to believe that the woman is a barometer of male power?

\section{PC: How did you come to your approach?}

AG: When, in my professional life, I decided to try and make sense of all the strange things that "never happened but always are," I ventured into a jungle of our collective 
imaginary. I sought to identify the visual and mental associations that had inexorably constructed the stereotype of the Snake Woman, and have continued to feed male fears of women. By being willing to get my hands dirty, I have been able unearth hidden but living evidence of an archetype that inseminated Western culture and its dualistic $^{1}$ and androcentric paideutic model.

\section{PC: I would never have thought that research into Snake Women would be so eventful!}

AG: So far, so good. It hasn't always been easy, but once I have got hold of a thread, I find it difficult to let go. When you start to untangle the skein it is often surprising how heartened you feel.

\section{PC: Well, let's talk a little about the ancient Greek myth of the Gorgon in particular, and how this story has shaped classical educational discourse in ancient Greece over the centuries; how much of it has been passed down to us in the 21st century?}

AG: Part of what's fascinating about this myth is the way the story has been interpreted in so many ways. My aim was to investigate the historical conditions that gradually defined subordinating symbols and conflictual values in social relations between the sexes. The book describes how the snakes and paralyzing gaze of the Medusa - the most widely standardized Snake Woman - have held a strangely vivid place in the visual arts and written sources over time, alongside largely negative emotions such as fear, anger, scorn and shame. So, I explored the outcomes and implications of the disturbing bond between the dangerous female gaze, the snake's malignitas, and the homicidal power of menstruation that has been threaded through the Western gender imaginary.

When you think about the history of female reptilian hybrids - from the pleasing Minoan Snake Goddesses to the depressing Gorgon, Echidna, Amazons, Eve, Melusine, Basilisk, Poisonous Maiden and Catoblepas of the Middle Ages, through to the Sadako/Samara and Medusa Cyborg of today - you are forced to question the "things that never happened but always are." The stories about Snake Women were not born dead, they are still creeping into our daily life.

\section{PC: Can you give us some examples of that?}

AG: They are not hard to find, especially in today's world of smartphones and search engines, and a quick image search will show you how this intriguing figure is portrayed: a fearsome gaze, surrounded by a crown of hissing snakes amongst a cumulus of petrified bodies; note the unemotional deathless stare, and the rivulet of blood - is she not something we are all afraid of, the very essence of our nightmares? If you want to 
understand what is really going on, my advice is to turn off all your screens, forget the pre-packaged figures you have seen, and imagine a mythological world in which a Snake Woman could appear unexpectedly, overturning the natural order of things. So, then, do the ancient myths have swift or broken wings?

When we stand in front of Medusa, surrounded by the scattered wreckage and debris of some ancient shipwreck, can we delude ourselves that we belong to a worthy band of treasure hunters? Or do we start to get the sinking feeling that we have actually joined a gang of grave robbers? Once you start asking questions such as these, it is difficult to stop; they come in a perpetual tide. Do the myths, as portrayed in literature and art, reflect human imagination, life, or could it be that they reflect both? As the trajectory of these myths throughout history is never linear, the threads overlap, change form, and intertwine, it is no easy task to unpick them. However, when you do, they often lead in surprising directions. It is surely no coincidence that the Roman historian Sallust (Gaius Sallustius Crispus), in the mid-first century BCE, suggested that such myths are among the strange "things that never happened but always are."

The traces of these "things that never happened" cannot be denied. They were continually projected, recounted, overheard, learned, imagined and felt by men and women alike; they permeate our individual and collective experiences. They stir the soul and our collective unconscious; they live and die as symbols, myths, metaphors, images, emotions, fairytales, ${ }^{2}$ and archetypes.

These archetypes should not be dismissed as mere concepts. They are strong evidence of our psychic structures, those that their inventor Jung ${ }^{3}$ understood were omnipresent features of our inner lives. Symbolic activity is a fundamental component of the idea of collective unconscious; it conceals impulses that determine how our personalities, identities and socialisation processes develop and evolve. Jung presupposed that archetypes are innate or inherited universal structures, but whatever the truth of this, it is clear that they function as a crucial nexus between our personal and public lives. We grow and are shaped by these "things that never happened," and the way in which this process occurs depends on several factors, among which is our sex.

\section{PC: So, are the Snake Women the targets of your research?}

AG: No, no, absolutely not, they are my incentive! I like to study everything underneath gender roles. We know that interpretations on symbolic thoughts warn us that age-old mythologies can't be deciphered using the traditional tools of reason and explanation. Instead, they suggest that we explore myths as alternative forms of intelligibility. And so, exploration of the paideutic value of the Medusa $\mathrm{myth}^{4}$ is a crucial starting point because it has met our emotional and intellectual needs since time out of mind.

\section{PC: And what emotive function does the myth perform?}


AG: Medusa, among the other Snake Women, is a prototype and archetype in the Western imagination; she was painted as the first female monster in the earliest visual and written sources (Homer and Hesiod). Since then her terrifying gaze and venomous locks have pervaded our art, religion, paideia and culture; although these symbols have been the subject of much reflection in numerous fields of the humanities and social sciences (literature, philology, science, archaeology, art, philosophy, anthropology, sociology, psychology and psychoanalysis), not much investigation has been done regarding her role in the field of history of education.

In order to analyse how beliefs regarding the destructive powers of Medusa have permeated public instruction, we have to examine how she has been portrayed in the stories passed down through the generations, paying particular attention to the idea of diversity, and the emotional dynamics in the history of gender. Over recent decades, historians - mainly women - have determined that Medusa, by virtue of her absolute and terrifying difference, plays an emblematic role as the absolute symbol of Otherness - an allegory for the conflictual relationships between man and woman. As I said earlier, we need to retrace how the myth of Medusa was used in the informal educational sphere, starting with the Classical and Medieval periods.

\section{PC: What, do you think, have been the milestones in the Snake Women's adventures?}

AG: Let us start with the Neolithic statues of ladies with winding legs in Europe (6000 $\mathrm{BCE}$ ), the easygoing eye idols representing the Mesopotamian goddess Ishtar (35003300 BCE), and the Snake 'goddesses' or priestesses at Knossos (1600 BCE). Then, in 6th-century Athens, they became malicious nocturnal creatures and monstrous heads. By focusing on the various identities of the Snake Woman over the centuries, we can see that she has come to epitomize the sub-humanity of the female. Bearing this in mind, my attention turned to the visual clichés employed to suggest the Otherness of the "second" sex, and the symbolic trickery that ascribed the female gaze its terrifying powers of petrifaction, in line with the contemporary and contextual theories on menstruation. But the more you uncover, the more there is to discover; it's like studying ancient frescoes and discovering that there are hidden images beneath, even more ancient and with very different messages to the "official" versions covering them.

\section{PC: That raises a specific question: in the periods you explore in your book, which social models did men and women learn from the Snake Women?}

AG: In a nutshell, the association of women with the legend of the deadly gaze has gathered strength since the Archaic period; Classical and Hellenistic literature and art indicate that the dangers of the Snake Woman were a major concern, and this developed into a real fixation in the Middle Ages. The Western obsession with serpentine creatures, so distinctively embodied by the Gorgons, originated in the 
Greco-Roman myths and permeated the art and literature of the centuries that followed. Over time, the female gaze became burdened with various complex messages associated with magical and symbolic forces, and this is the message we receive from the visual and written sources. European folklore is full of references to the peculiar affinity between women and snakes - a reverberating alliance tainted with the stain of menstrual blood - and this fuelled belief in Medusa's signature power: the evil eye. Medusa's gaze thereby became the leitmotif of a phenomenon that represented a wide variety of emotional threats to Medieval society; in line with the theological and moral framework of the time, Dante believed that her paralyzing glance would bring about spiritual death; she inspired terror in Walter Map's stories of necrophilia, and aroused blind sensuality in Jean de Meun's poetic impressions.

\section{PC: What is the most compelling thing left to us by the Medieval imaginary?}

AG: There are so many things to choose from! As I talk about in the third chapter of my book, the second millennium brings us face to face with those "things that never happened" - things which often cause us to shut our eyes; here the focus shifts to mediaeval reformulations of this legend and the seductive ways in which a widespread belief in the dangerousness of the female stare was bestowed the power of lived experience, pulling it down into the mysterious vortex of menstruation. In the nocturnal regime of the Mediaeval imaginary, as approached by Gilbert Durand, ${ }^{5}$ water, lunar rhythms, flowing hair, snakes, eyes and menstrual blood all absorbed the negative shades contained in these stories of evil femininity.

This concern of the glare was exacerbated by the mediaeval Church's convincing disciplina oculorum teachings. As the system endorsing witch hunts in Christian Europe emerged, theologians, doctors and clerics spread the idea that a woman's eyes were capable of transmitting deadly poison, and could render a man dumb or mad. They could wither his emotions and make him ill, or even kill him outright. And yet the lures of the Snake Women still appealed to Anglo-Saxon, Italian, French and German folklore. The implausible yet effective snakes that quietly preconceived natural and social hierarchies and moral conflicts in the ancient and Judeo-Christian traditions were likewise both admired and feared.

From the 12th century onward, Eve's snake seducer, the snake-dragon of the Apocalypse, the unsettling Basilisk and all the hissing creatures illustrated in the pages of the Bestiaries were the vehicles for the impressive debut of Otherness in Mediaeval society. Then, during the 13th century, the snake's mediaeval metamorphoses into feminine figures drew the Basilisk, Salamander and Hydra closer to menstruating and menopausal women. According to the language of the age, all of these were creatures full to bursting with "highly deadly humours." Think of Eve, ubiquitous in the art of the late Middle Ages ( $\mathrm{H}$. Bosch) and Renaissance (Michelangelo), portrayed as a snake in the guise of a female humanoid. There are many artistic, religious, literary and scientific 
examples of the aversion to female figures perceived to be allied with serpents: Eve, Melusine, the Poisonous Maiden and the menstruating woman. These "monstrous" women would prove both appealing and enduring, and not even the French aesthetic ambition to understand and embrace Otherness - as expressed by the courtly poets and novelists whose works dealt exclusively with the sense of sight -was capable of putting a dent in the picturesque psychic barriers that elevated men so far above women.

Despite all the opposition, however, Hildegard von Bingen, Trotula de Ruggiero and Christine de Pizan - three singular female writers - stood against the corrupting phenomenal forms of the Snake Woman and showed us the way to healing. At the beginning of the 15th century, de Pizan resisted taking for granted the usual sinister portrayal of Medusa and, in a liberating sense, transformed her into shining and positive figure, more splendid even than the beautiful yet helpless Medusas of Classical art.

\section{PC: What impact have the numerous writers, fathers of the church, theologians, natural philosophers, physicians and artists eager to portray Medusa and Eve as Other had on past lives and today's society?}

AG: Of course, we're talking now about Christian representations. The Medieval worldview betrays a mindset that was closely structured around the symbolism semanticization - of humanity and reality; in the hierarchy of Creation, every living piece of the puzzle had a significance based on its equivalent relationship with the corresponding sections. Hence, both the religious and secular authorities of the 12thcentury "Renaissance," like the physiognomists of Antiquity, endeavoured to tease out subtle connections between the animal kingdom, phenomenology and human behaviour. Like their Hellenistic predecessors, they relied on the tangible evidence of paintings and sculptures, but, unlike them, they did not base their parallels with the natural world on empirical findings. Instead, they trusted in symbolism, thereby sealing the serpent's fate; the snake's character was now explained through its unflattering potential parallels with humanity and morality.

Then, from the 13th century onwards, the Basilisk, Salamandra and Hydra were used to represent the perfidy of menstruating and menopausal women. This was hugely successful, and there are several examples which, although not providing the basis for sweeping generalizations, enable us to make out - as Durand suggested - the intimate connection between things that would remain incomprehensible if we considered them as isolated phenomena. In the complex network of these equivalencies, there are two cases that stand out from the crowd: the resonance between Eve and the serpent and the analogy of the Basilisk and its murderous stare, and the likening of other uncommon female figures with equally poisonous powers to menstruating women. 
These parallels helped forge new models for female identity in the Medieval West. Not content with Eve, they used Mélusine, the 14th-century serpent-fairy said to have given rise to the noble House of Lusignan; she was obviously a direct descendent of Echidna, bearing her residual anger with a hint of nostalgia for a past in which blood was not a negative force.

It is sad to say, though, that these echoes of a more benign past would only add fuel to the fire of the Western collective imaginary; this dictated that menstruating women should be shunned, because their powerful gaze - akin to that of the Basilisk would undoubtedly cause some natural disaster. In other words, women represented a major threat to society, and this message was transmitted loud and clear through the symbolic, rather than scientific, references in the literature and iconography, as well as religious and spiritual doctrines, philosophical and medical theories, and moral education. This fire was not even remotely doused by the fervour for naturalistic investigation that started to pull people's hearts and minds away from the Church in the 13th century. The origins of this shift are clear from the French pedagogical work Placides et Timéo, but even this treatise was not adequate to dispel the aura of menace that permeated relationships between the sexes. Dangerous women and their serpent alliances - especially Eve, the menstruating woman and the Poison-Damsel represented one of the most enduring cultural phantasms, and this idiosyncrasy continued to influence the figurative, religious, scientific and pedagogical imaginary throughout the ensuing centuries.

\section{PC: You offer us a lot of visual evidence from across the centuries; what have artists made of the Snake Women?}

AG: I'm glad you asked; I think that in the investigation of such symbolic phenomena we need to use as many different kinds of sources as we can get our hands on. And images are important historical sources. Several studies have shown that even in the art of the 7th century BCE, which was heavily influenced by non-Hellenistic sources, females were depicted as monstrous. Medusa's face betrays all the basest, most confused and predatory emotions: rage and aggressiveness, which were also characteristic of the animal kingdom. And, as they say, the face is the mirror of the soul.

This belief is evident from the first treatises on physiognomy, which, in the 5th century BCE, based an entire 'scientific' discipline on this multifaceted and tortuous tradition; Aristotle and his disciples were firmly convinced that a person's character could be divined by analysing their physical features and facial characteristics. Thus, Medusa's decapitation at the hands of Perseus and the wily serpent became effigies of evil, and the unbreakable association between women and a malevolent nature continued throughout the Middle Ages, whose iconography is dominated by images of one of the primary stand-ins for Medusa, namely Eve, the mother of all our sins. 


\section{PC: Persistent too are the other repulsive mainstays of Medusa iconography, the slithering snakes and the fatal gaze. Is this by accident or design?}

AG: These two features were the main characteristics associated by Medieval and Modern-Age physicians and theologians with the toxicity of menstrual blood and the physical 'imperfection' of the female of the human species. Across the centuries, the theory of the four humours explained that a build-up of waste in women's bodies was responsible not only for their illnesses, but also their menstrual cycle. It was a logical conclusion, therefore, that intimate coupling with women during menstruation would be dangerous for men. This caution was extended to menopausal women, whose powers of contamination were believed to be far worse - so much so that they even threatened the safety of children! The recurring faces of the Snake Women in art seem to be inextricably linked to these ideas; they establish an intermittent but concrete connection with the past. Think of the sinister infective energy of the Medusas painted by Caravaggio, Rubens and the anonymous Flemish artist, and many others working in the 16th and 17th centuries; they provoke the same horror, repulsion and disgust as their Ancient Greek, Hellenistic and Roman counterparts. Furthermore, as sculptures from Greece's Archaic Era were unearthed at the end of the 19th century, this caused another dramatic and powerful resurgence in the fame of the gorgoneia and their menacing otherworldly gifts.

The stereotypes portrayed in these images were almost universally accepted, and would continue to shape social behaviour for centuries to come. Hence the artists, who acquired an extraordinary degree of influence over Western imagination and thought, are partially to blame for our ready assimilation of such slanderous lies; the gaps in our education left by the disappearance of our Western institutions left room for the widespread diffusion of such images, which, thanks to their close ties with oral history, consolidated our gender identities. The pedagogical power of the frescoes, mosaics and carvings in our public buildings - especially in German and French Gothic cathedrals - and the illustrations in the Bestiaries made the danger that could be caused by women consorting with snakes very clear. Whereas in the Old World these had once been emblems of sagacity and strength, thanks to the Book of Genesis, the temptation in the Garden of Eden became the predominant depiction of the female of the species. Eve's fall was a recurring theme in the figurative arts, which culminated in Michelangelo's Sistine Chapel (1508-1512). In art, women were portrayed to the left of men, on the side of imperfection and sin, and many images showed reptiles with female human heads.

Take, for instance, Masolino da Panicale's Eve, which I chose for the picture on the cover of my book, for example. In it, he painted the serpent snaking around the trunk of the Tree of Knowledge as a reflection of Eve, with the same idealized beauty and golden tresses, and its sinuous curves mirror the arch of her arm. In fact, by the 14th century, she and the serpent had become interchangeable, and some paintings even 
omitted the serpent altogether - Eve alone was sufficient to convey the idea.

Interestingly, some paintings even show the Devil with breasts, and his hair started to become suspiciously snake-like in the 9th century - a persistent attribute that was directly inherited by the witches. Thus, the fable of the Garden of Eden became reality.

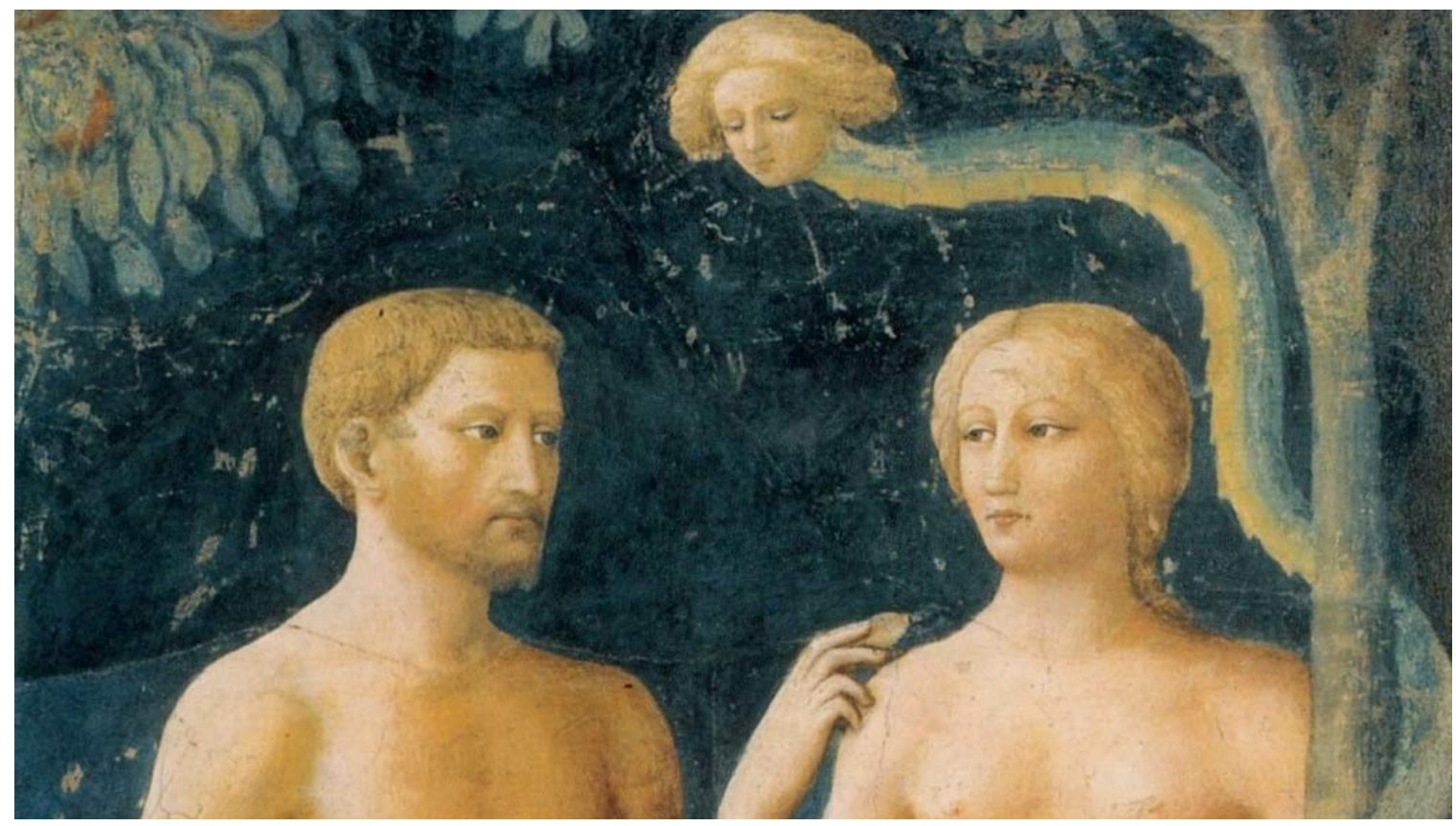

Masolino da Panicale, Temptation of Adam and Eve (fresco, 1426-27, Chapel Brancacci, Santa Maria del Carmine, Florence).

Take too another example of a monstrous female, this one by Giotto, who painted Envy in the Scrovegni Chapel (1303-1305) as a repellant old hag. This decrepit Envy looks more ill than sinful. However, she too, like the Gorgon, has horns and rolling eyes. It will come as no surprise to you, I'm sure, that she also has a poisonous snake bursting out of her mouth; it turns back on itself so that its image is reflected in her eyes. What is more, Envy's outstretched hand mimics the menacing mouth of the snake, and her gaze speaks volumes about the anguish of the scene. Once again, a woman's gaze is capable of warping the minds, bodies and planets.

Although the same symbols of womanly corruption are repeated over and over again in these images, the artists were not as explicit as the writers; they only hinted at the powers of menstrual blood, using the serpent, which was echoed in the flowing locks and/or wrinkled and drooping appearance of women. In the 13th century, artists began to paint reptiles and mirrors with the same energy that they had expended on depicting the Virgin in the 12th century.

PC: Bearing in mind these different stages helps us to understand the legacy left by such stories and images - an angry look, hissing hair and toxic blood; can you sum up for us the complexity of this process? 
AG: Of course! Our modern-day vision of the Snake Women has primarily been moulded by Classical Greek and Judeo-Christian influences. From that time onwards, the snake has been used in various contexts to allude to evil, sin, paganism, chaos and death. In the Late Medieval, though the prevailing cultural standards associated other female figures with the serpent, it was the snake-crowned head of Medusa and the central legend of Eve's Fall that were used to define the nature of the female. Tales and images of women and serpents explained to the public that women were naturally degenerate, the causes of human suffering, and this guided the education of both women and men.

PC: I wonder what you think of this enduring legacy. Has it triggered some kind of long-term rethinking of how we approach the history of education?

AG: In my eyes, yes. I, for example, could have approached this topic from many angles, but most would have been unsuitable or even boring and monotonous. Instead, I chose to illustrate how Medusa's gaze and serpents have shone strangely in the imagination of various past societies. It is by reflecting negative social emotions such as anger, scorn, shame and fear, that the bond between these two figures has preserved the gender hierarchy, being cemented in our educational models.

PC: It looks like, for now at least, we have to come to the end of the road; what do you think we should take away from this journey?

AG: In my opinion, it is vital to understand that, devoid of imaginary and emotions, history would be empty. This is an especially important point to bear in mind for those who would study the past in order not to repeat it, but to free themselves from its shackles. We must shake off the symbols we have inherited from patriarchal society, which used education to consolidate ideas of gender hierarchy, and the destructive Medusa as a means of self-preservation.

\section{PC: What about today? Are the Snake Women taking on new meanings?}

AG: Undoubtedly. As I show in the book, they have always had the gift of metamorphosis. And it was Christine de Pizan $^{6}$ - who you know very well - that taught us how to behave. She made an acute contribution to the discussion on the choices that we have to make today. She not only sought to overturn the logical categories that prevailed in 14th-century educational culture, but also to subvert our imaginary; she altered its present and future course. In de Pizan's fictional accounts, Medusa and Eve evoke very different feelings: she transformed them into luminous and wholesome symbols. ${ }^{7}$ She had discovered that the category of contraposition could be replaced by that of transformation. She, in her Book of the Cities of Ladies, chose to invent new stories, new images - threads that could be woven into a web of female cooperation 
and social harmony, like living pilasters of a new system of education. This was a most sympathetic flash, out of the blue in the history of education.

After all, didn't Oscar Wilde say that the proper occupation of the historian was to provide an accurate description of what never occurred?

\section{PC: Thank you very much, Angela; this has been a really captivating conversation!}

AG: Well, it was very pleasant exchange for me too! And I just want to say, dear Patrizia, I truly look forward to seeing you again.

\section{Notes}

1. See H.I. Marrou, History of Education in Antiquity (Wisconsin: Wisconsin University Press, 1956), specifically Part One, Chapter III, "Masculine Love as a Method of Education" (pp. 22-30).

2. For the representation of heroines and their archetypes in narratives according to the principles of Jungian analytical psychology, see M.L. Von Franz, Problems of the Feminine in Fairy Tales (New York: Spring Publications, 1972).

3. C.G. Jung, The Archetypes and the Collective Unconscious [1948], in Collected Works of C.G. Jung, Vol. 9 (Part 1), (Princeton, N.J.: Princeton University Press, 1969), 207-254.

4. For a Freudian analysis of the educational power of mythological narrative in the Classical paideia, see B. Bettelheim, The Uses of Enchantment: The Meaning and Importance of Fairy Tales (New York: Knopf, 1976). Plus, for a stimulating look at the ancient Greek concept of emotions as dynamic forces in social relations and ethical education, see also D. Konstan, The Emotions of the Ancient Greeks: Studies in Aristotle and Classical Literature (Toronto: University of Toronto Press, 2006).

5. On this subject, see G. Durand, The Anthropological Structures of the Imaginary (Brisbane: Boombana Publications, 1999).

6. See Christine de Pizan. The Woman Writer and the City, edited by P. Caraffi (Firenze: Alinea, 2009).

7. Five hundred years later, Helen Cixous, with unprecedented creativity and autonomy of thought, also discerned in Medusa a pleasing spark of insouciance and vital tension. See H. Cixous, "The Laugh of the Medusa," Signs 1, no. 4 (1976). 